\title{
Mitotic checkpoint genes in budding yeast and the dependence of mitosis on DNA replication and repair
}

\author{
Ted. A. Weinert, ${ }^{1,2,3}$ Gretchen L. Kiser, ${ }^{1}$ and L.H. Hartwell ${ }^{2}$ \\ ${ }^{1}$ Department of Molecular and Cellular Biology, University of Arizona, Tucson, Arizona 85721 USA; ${ }^{2}$ Department \\ of Genetics, University of Washington, Seattle, Washington 98195 USA
}

In eukaryotes a cell-cycle control termed a checkpoint causes arrest in the $S$ or $G_{2}$ phases when chromosomes are incompletely replicated or damaged. Previously, we showed in budding yeast that RAD9 and RAD17 are checkpoint genes required for arrest in the $G_{2}$ phase after DNA damage. Here, we describe a genetic strategy that identified four additional checkpoint genes that act in two pathways. Both classes of genes are required for arrest in the $G_{2}$ phase after DNA damage, and one class of genes is also required for arrest in $S$ phase when DNA replication is incomplete. The $\mathrm{G}_{2}$-specific genes include $M E C 3$ (for mitosis entry checkpoint), RAD9, $R A D 17$, and $R A D 24$. The genes common to both $S$ phase and $G_{2}$ phase pathways are $\overline{M E C 1}$ and $M E C 2$. The $M E C 2$ gene proves to be identical to the RAD53 gene. Checkpoint mutants were identified by their interactions with a temperature-sensitive allele of the cell division cycle gene $C D C 13$; $c d c 13$ mutants arrested in $G_{2}$ and survived at the restrictive temperature, whereas all $c d c 13$ checkpoint double mutants failed to arrest in $G_{2}$ and died rapidly at the restrictive temperature. The cell-cycle roles of the RAD and MEC genes were examined by combination of rad and mec mutant alleles with $10 \mathrm{cdc}$ mutant alleles that arrest in different stages of the cell cycle at the restrictive temperature and by the response of $\mathrm{rad}$ and mec mutant alleles to DNA damaging agents and to hydroxyurea, a drug that inhibits DNA replication. We conclude that the checkpoint in budding yeast consists of overlapping S-phase and $G_{2}$-phase pathways that respond to incomplete DNA replication and/or DNA damage and cause arrest of cells before mitosis.

[Key Words: Checkpoints; DNA replication and repair; budding yeast; cell-cycle control]

Received November 15, 1993; revised version accepted January 20, 1994.

The eukaryotic mitotic cell cycle proceeds by a series of events essentially invariant in their order; DNA replication is completed before mitosis, chromosome condensation before chromosome segregation, and mitosis before cell abscission (for review, see Hartwell and Weinert 1989; Murray 1993). The order is maintained by mechanisms that ensure the dependence of events, where late events require the completion of early events. A checkpoint is one type of mechanism that ensures the dependence of events, and studies from a variety of organisms demonstrate that a checkpoint ensures the dependence of mitosis on DNA replication (for review, see Hartwell and Weinert 1989; Murray 1993). Checkpoints appear to govern the dependence of other cell-cycle events as well [e.g., initiation of DNA replication (Kastan et al. 1991; Kuerbitz et al. 1992); chromosome segregation (Hoyt et al. 1991; Li and Murray 1991)], though some dependencies may be governed by controls other than checkpoints.

The mitotic checkpoint addressed here provides a cell the time to complete DNA replication and repair DNA

${ }^{3}$ Corresponding author. damage before mitosis. This function has two related consequences for the cell. First, the checkpoint ensures that cells maintain genome integrity (e.g., remain euploid) despite the low but continuous levels of DNA damage that occur in normal cell division. Second, the checkpoint allows cells to withstand episodic DNA damage or delays in DNA replication These two consequences of checkpoint function are inferred from genetic studies of yeast mutants; the checkpoint null mutant rad $9 \Delta$ is viable but mutant cells do lose chromosomes spontaneously when unperturbed (without radiation) at a higher rate than do wild-type cells, and rad9 9 cells are sensitive to radiation (Weinert and Hartwell 1990).

Other cell-cycle checkpoints apparently play similar but more complex roles than that of the RAD9 gene. Yeast cells defective for the checkpoint gene $M A D 2$ are unresponsive to a defect in microtubule structure or function: mad2 mutant cells with disrupted microtubules continue the cell cycle and die, whereas wild-type cells arrest and remain viable (Li and Murray 1991). MAD2 plays a role in genomic stability because mad2 mutants (in unperturbed cells) lose chromosomes at a higher rate than wild-type cells. $M A D 2$ is an essential 
gene; therefore, the checkpoint is either essential for normal cell division or it is nonessential and $M A D 2$ has a second essential cellular function. [Recent studies show that Mad2p can act as a prenyltransferase that effects protein trafficking (Jiang et al. 1993; Li et al. 1993)] The p53 gene in mammalian cells also acts in a cell-cycle checkpoint early in cell division (Kastan et al. 1991; Kuerbitz et al. 1992). Like RAD9, the p53 gene is not essential for cell viability (Donehower et al. 1992) but does provide for genomic stability because p 53 mutants suffer gene amplification and chromosome loss (Livingston et al. 1992; Yin et al. 1992). p53 mutant cells, however, are not radiation sensitive (Lee and Bernstein 1993; Slichenmeyer et al. 1993), perhaps because they do have an intact $G_{2}$ checkpoint and can still complete DNA repair before mitosis.

Studies of the p53 gene also reveal a relationship among cell-cycle checkpoints, genomic stability, and cancer (see Hartwell 1992; Weinert and Lydall 1993). The p53 gene is found mutated in most types of human cancers. Cancer may arise more rapidly in p53 mutant cells than in wild-type cells because the checkpoint defect in mutant cells results in genomic instability and accumulation of mutations that contribute to abnormal growth.

We began dissecting the mitotic checkpoint that orders DNA replication and mitosis in the budding yeast Saccharomyces cerevisiae. By examining available radiation-sensitive mutants, we showed that the $R A D 9$ and $R A D 17$ genes are essential for cell-cycle arrest in the $\mathrm{G}_{2}$ phase after DNA damage (Weinert and Hartwell 1988, 1990, 1993; Hartwell and Weinert 1989). The roles of the $R A D 9$ and $R A D 17$ genes were evaluated by comparing the cell-cycle responses of mutant and wild-type cells to radiation and to a drug that inhibits DNA replication (hydroxyurea); rad9 and rad17 mutants failed to arrest after irradiation (X- or UV-), but did arrest when treated with hydroxyurea. In addition the $R A D 9$ and $R A D 17$ genes also showed a striking genetic interaction with a class of $C D C$ genes that encode structural genes for DNA replication enzymes, including DNA ligase (CDC9; Johnston and Nasmyth 1978); DNA polymerase $\alpha$ (CDC2; Sitney et al. 1989), DNA polymerase $\gamma$ (CDC17; Johnson et al. 1985; Carson 1987), and CDC13 [whose function in DNA replication is inferred from genetic analysis (Hartwell and Smith 1985)]. For example, DNA ligase mutants $(c d c 9)$ arrested in the $\mathrm{G}_{2}$ phase (determined by flow cytometryl and remained viable after shift to the restrictive temperature, whereas $c d c 9$ rad 9 and $c d c 9$ rad 17 double mutants failed to cell-cycle arrest and lost cell viability more rapidly. The inactivation of the $c d c$ mutant gene product apparently leads to DNA lesions that trigger arrest at the checkpoint. Cell death is probably attributable in part to cell division with unrepaired DNA breaks, although additional causes of death may include defects in DNA repair and/or defects in direct gene product interactions (e.g., defective interaction between the mutant DNA ligase and the mutant checkpoint gene protein). Failure to arrest in the $G_{2}$ phase after radiation and after inactivation of DNA rep- lication enzymes argues that the checkpoint genes are essential for arrest in the $G_{2}$ phase after DNA damage. [We cannot distinguish whether the four mutants $c d c 2$, $c d c 9, c d c 13$, and $c d c 17$ arrest in the late $\mathrm{S}$ phase or in the $\mathrm{G}_{2}$ phase after shift to the restrictive temperature. Flow cytometry used to measure DNA content is not sensitive enough to distinguish the two possibilities. For simplicity, we will refer to arrest in the $G_{2}$ phase in these $c d c$ mutants but acknowledge the ambiguity (for further discussion, see Weinert and Hartwell 1993)].

The striking interaction of $R A D 9$ and $R A D 17$ with $C D C$ genes suggested the genetic strategy used here to identify additional checkpoint genes. We have used the observation that after shift to the restrictive temperature, $c d c 13$ mutant cells arrest and remain viable, whereas $c d c 13$ - checkpoint double mutants fail to arrest and die more rapidly. We identify alleles in four checkpoint genes, MEC1, MEC2 (RAD53), MEC3, and $R A D 9$, and also describe studies on a sixth checkpoint gene, RAD24, found by screening RAD mutants. Our studies show that all four genes are essential for arrest in the $G_{2}$ phase after DNA damage and that two of these genes have an additional role in arrest in early $S$ phase when DNA replication is blocked. The mitotic checkpoint has discrete $S$-phase and $G_{2}$-phase pathways.

\section{Results}

\section{Identification of four additional checkpoint genes}

We devised a genetic screen for checkpoint mutants based on the observation that $c d c 13$-checkpoint double mutants failed to arrest in the $G_{2}$ phase and died rapidly after shift to the restrictive temperature (Fig. 1) (Weinert and Hartwell 1993|. cdc13 mutants are defective for the metabolism of telomere-associated DNA; they accumulate single-stranded DNA in regions near the ends of chromosomes at the restrictive temperature (B. Garvik and L.H. Hartwell, pers. comm.). We inferred that these DNA lesions cause arrest at the checkpoint and that the low cell viability of $c d c 13$-checkpoint double mutant cells may be attributable to cell division with unrepaired DNA lesions (though other explanations are possiblediscussed below). cdc13 mutants were chosen for the genetic screen, instead of other $c d c$ mutants (e.g., $c d c 9$; DNA ligase), because $c d c 13$-checkpoint double mutants have the most dramatic arrest-defect phenotype (Fig. 1A,B) (see Hartwell and Weinert 1989; Weinert and Hartwell 1993).

We mutagenized $c d c 13$ cells (strain TWY146, see Table 1 ) and first screened for strains that died rapidly (the rapid death phenotype) and then identified mutants that failed to cell-cycle arrest after shift to the restrictive temperature (the $c d c 13$ arrest-defect phenotype; see Materials and methods). Of $\sim 12,000$ ethylmethane sulfonate (EMS)-mutagenized cells screened, $\sim 500$ strains died more rapidly than a $c d c 13$ strain and 21 of these strains also failed to cell-cycle arrest after shift to the restrictive temperature. 


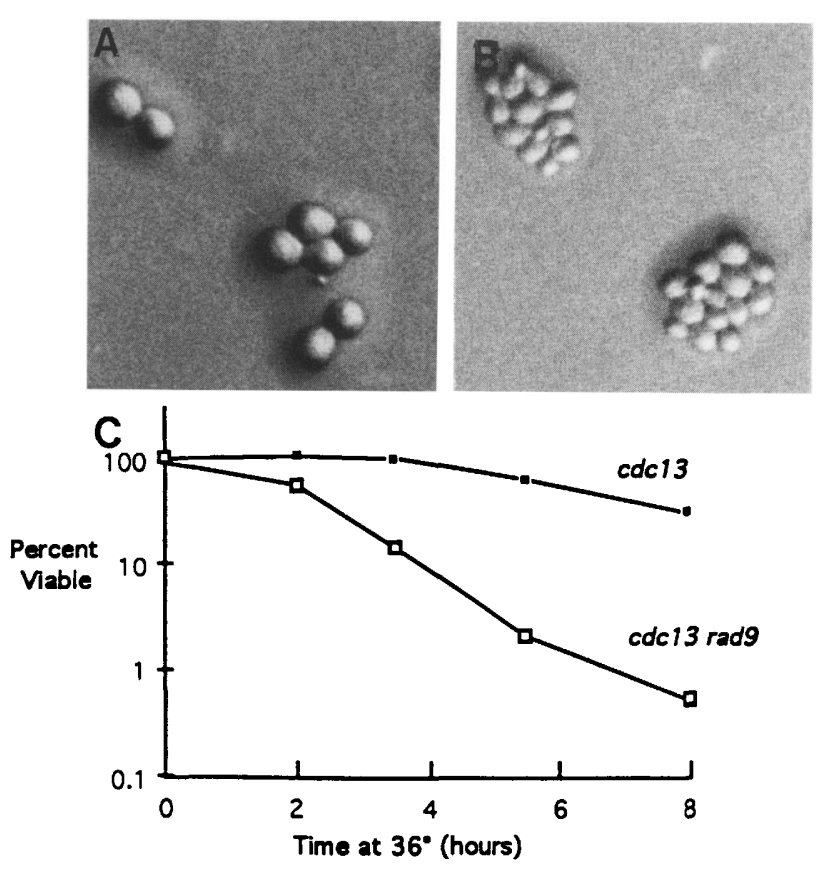

Figure 1. $c d c 13$ cells arrest in the first cell cycle and retain cell viability, whereas $c d c 13$ rad9 cells fail to arrest and lose viability more rapidly. $c d c 13(A)$ and $c d c 13 \mathrm{rad} 9(B)$ cells grown at the permissive temperature were placed on agar plates and shifted to the restrictive temperature of $36^{\circ} \mathrm{C}$ for $10 \mathrm{hr}$. Each microcolony arose from a single cell. Cells were photographed at the same magnification. $(C) c d c 13$ and $c d c 13$ rad 9 cells grown at the permissive temperature were shifted to the restrictive temperature of $36^{\circ} \mathrm{C}$ in liquid culture, at various times cells were plated at the permissive temperature $\left(23^{\circ} \mathrm{C}\right)$, and cell viability was determined by colony formation after incubation for 2-3 days. The average of duplicate cultures is shown.

\section{Genetic characterization and mapping of checkpoint mutants}

In each mutant analyzed the $c d c 13$ arrest-defect and rapid death phenotypes cosegregated and were attributed to single mutations (see Materials and methods). All 21 mutants were recessive to wild type and formed four complementation groups, with multiple alleles of mec1, mec2, and rad 9 and a single allele of mec3 (Table 2). In a separate screen of radiation-sensitive mutants, we found that rad24-1 is also a checkpoint mutant and included it in further analyses. In our genetic screen we did not identify any alleles of the checkpoint mutant rad17 or that of rad24. We have now screened rad6, 8, 9, 10, 11, 12, 17, $18,24,52,53$ (identical to mec2), and rad54 (this study, Weinert and Hartwell 1988; unpubl.).

mec1 identifies a previously undescribed gene and maps to the long arm of CHRII between lys2 and cdc28 (Table 3). The genetic mapping was confirmed by results of DNA sequence analysis; $M E C 1$ is immediately adjacent to but distinct from $C K S 1$, which was mapped to the same chromosomal region (Hadwiger et al. 1989; unpubl.). mec2 maps to CHRXV and proved to be allelic with rad53-1; both mec2-1 and rad53-1 alleles confer sensitivity to hydroxyurea (HU sensitivity) and fail to complement each other for HU sensitivity, and meiotic analysis shows that the mutations are tightly linked (Table 3|. MEC3 maps physically to CHRIV and is neither RAD55 nor $R A D 9$, but we have not yet identified its chromosomal location (see Materials and methods).

\section{Checkpoint mutants are sensitive to DNA-damaging agents and fail to cell-cycle arrest after X-irradiation}

We tested the newly isolated checkpoint mutant alleles for their responses to DNA-damaging agents and found that at least some alleles of each checkpoint gene were methylmethane sulfonate (MMS)-, UV-, and X-ray sensitive (Table 2; data not shown). Some alleles of mec1 and mec2 showed a complex spectrum of phenotypes (see Discussion).

On the basis of their radiation and drug sensitivities, the strongest alleles from each complementation group, mec1-1, mec2-1, and mec3-1, were selected for further studies. We also tested the strongest alleles for each gene for cell-cycle arrest after X-irradiation and found that each failed to arrest in the $G_{2}$ phase after DNA damage (Table 4).

The strongest allele for each checkpoint gene appears to be a nonconditional mutant for checkpoint function. Although the $c d c 13$-arrest defect phenotype was necessarily determined at $36^{\circ} \mathrm{C}$, we found that the same mutants tested at $23^{\circ} \mathrm{C}$ were arrest-defective after X-irradiation and were DNA damage sensitive (X-ray, UV, and MMS). Whether alleles other than mec1-1, mec2-1, and mec3-1 are temperature sensitive for function has not been examined. mec1-1, mec3-1, and rad24-1 all grow well at $23^{\circ} \mathrm{C}$ and at $36^{\circ} \mathrm{C}$ (in $C D C^{+}$strains), and mec2-1 grows well at lower temperatures but not at $36^{\circ} \mathrm{C}$ (see Table 5).

\section{Interaction of checkpoint and $\mathrm{CDC}$ genes}

The roles of the checkpoint genes were examined by interactions with $C D C$ genes that act at specific stages of cell division. We introduced each checkpoint mutation into $c d c$ mutants that arrest after shift to the restrictive temperature in either the $\mathrm{G}_{1}$ phase $(c d c 28)$; in $\mathrm{G}_{1}-\mathrm{S}$ $(c d c 7)$; in $\mathrm{S}$ phase $\left(c d c 8\right.$ and $c d c 17$ at $\left.38^{\circ} \mathrm{C}\right)$; in $\mathrm{G}_{2}$ phase $\left(c d c 2, c d c 9, c d c 17\right.$ at $34^{\circ} \mathrm{C}$, and $c d c 13 \mid$; in $\mathrm{G}_{2}-\mathrm{M}$ phase (cdc16); or in postanaphase (cdc15). We classify the arrest of $c d c 16$ mutants as in $\mathrm{G}_{2}-\mathrm{M}$ although we have no formal proof that the arrest point is distinct from the class of $c d c$ mutants that arrests in the $\mathrm{G}_{2}$ phase. The cdc16 mutant is distinctive in that it does not generate DNA damage at the restrictive temperature as does the other class of $c d c$ mutants that arrest in $\mathrm{G}_{2}$ (for discussion, see Weinert and Hartwell 1993). cdc6 mutants were also analyzed and arrest apparently early in nuclear division (see Discussion). The stages of arrest are based on previous observations, including genetic, morphological, and flow cytometric analyses (see Pringle and Hartwell 1981; Carson 1986; Weinert and Hartwell 1993). The interactions of $C D C$ and checkpoint genes were assessed by comparing the $c d c$ single mutants with the corre- 
Table 1. Strains used in this study

\begin{tabular}{|c|c|}
\hline Strain & Genotype \\
\hline TWY397 ${ }^{\mathrm{a}}$ & MATa ura3 his7 leu2 trp1 \\
\hline TWY398 & MATa rad9D::LEU2 his7 ura3 leu2 trp1 \\
\hline TWY308 & $M A T \alpha$ mec1-1 ura3 trp1 \\
\hline TWY312 & MAT $\alpha$ mec2-1 ura3 his7 trp1 \\
\hline TWY316 & MATa mec3-1 ura3 his3 trp1 \\
\hline TWY399 & $M A T \mathbf{a}$ rad24-1 ura3 his7 leu2 trp1 \\
\hline TWY123 ${ }^{\mathrm{a}}$ & $M A T \alpha / M A T a$ ura3/ura3 his3/+ his $7 /+$ leu2/leu2 trp1/trp1 \\
\hline TWY162 & MATa/MATa mec1-1/mec1-1 ura3/ura3 his3/ + his $7 /+$ leu2/ + cdc13/+ \\
\hline TWY409 & $M A T \alpha c d c 2-2$ his 7 \\
\hline TWY410 & MATa cdc2-2 mec1-1 ura3 ura1 \\
\hline TWY411 & MAT $\alpha$ cdc2-2 mec2-1 ura3 his3 his 7 \\
\hline TWY412 & $M A T \alpha c d c 2-2$ mec3-1 his 7 \\
\hline TWY413 & MAT $\alpha$ cdc2-2 rad24-1 ura3 ura1 his7 leu2 \\
\hline TWY414 & MAT $\alpha$ cdc6-1 ura3 ura1 \\
\hline TWY415 & $M A T \alpha$ cdc6-1 mec1-1 ura1 trp1 \\
\hline TWY416 & $M A T \alpha c d c 6-1$ mec2-1 \\
\hline TWY417 & $M A T \alpha$ cdc6-1 mec3-1 ura3 ura1 his7 trp1 \\
\hline TWY418 & MATa cdc6-1 rad24-1 ura3 ura1 his7 \\
\hline TWY419 & $M A T \alpha c d c 7-4$ ura1 \\
\hline TWY420 & $M A T \alpha c d c 7-4$ mec1-1 ura1 his7 \\
\hline TWY421 & MAT $\alpha$ cdc7-4 mec2-1 ura3 his7 \\
\hline TWY422 & MAT $\alpha$ cdc7-4 mec3-1 ura1 his7 \\
\hline TWY423 & MAT $\alpha$ cdc7-4 rad24-1 ura3 his 7 leu2 \\
\hline TWY424 & MATa $c d c 8-1$ \\
\hline TWY425 & MATa cdc8-1 mec3-1 ura1 his7 leu2 trp1 \\
\hline TWY426 & MAT $\alpha$ cdc8-1 rad24-1 ura1 his7 leu2 \\
\hline TWY54 & MAT $\alpha$ cdc9-8 ura3 ade3 ade2 trp1 leu1 can1 cyh2 sap3 trp1 SCE::URA3 \\
\hline TWY285 & MATa $c d c 9-8$ mec1-1 ade2 ade3 ura3 trp1 leu ${ }^{-}$ \\
\hline TWY283 & $M A T \alpha c d c 9-8$ mec2-1 ura3 his3 trp1 leu ${ }^{-}$ \\
\hline TWY429 & MAT $\alpha$ cdc9-8 mec3-1 his7 trp1 \\
\hline TWY430 & MATa cdc9-8 rad24-1 his7 leu2 trp1 ade3 \\
\hline TWY431 & MATa cdc13-1 ura3 his3 \\
\hline TWY432 & MAT $\alpha$ cdc13-1 mec1-1 ura3 his3 his7 leu2 \\
\hline TWY433 & MAT $\alpha$ cdc13-1 mec2-1 ura3 \\
\hline TWY434 & MATa cdc13-1 mec3-1 ura3 his7 leu2 trp1 \\
\hline TWY435 & $M A T \alpha$ cdc13-1 rad24-1 mec3-1 ura3 his3 trp1 \\
\hline TWY436 & MATa $c d c 15-1$ ura1 ura3 his3 his7 \\
\hline TWY437 & MATa cdc15-1 mec1-1 ura3 his7 \\
\hline TWY438 & MAT $\alpha$ cdc15-1 mec2-1 his7 trp1 \\
\hline TWY439 & MAT $\alpha$ cdc15-1 mec3-1 ura1 his7 \\
\hline TWY440 & MATa cdc15-1 rad24-1 ura3 his7 trp1 \\
\hline TWY441 & MATa $c d c 16-1$ ura1 ura3 his7 \\
\hline TWY442 & $M A T \alpha c d c 16-1$ mec1-1 \\
\hline TWY443 & MATa cdc16-1 mec2-1 ura3 trp1 \\
\hline TWY444 & MATa $c d c 16-1$ mec3-1 his7 trp1 \\
\hline TWY445 & MATa cdc16-1 rad24-1 ura1 ura3 his7 \\
\hline TWY446 & MATa cdc17-1 his7 \\
\hline TWY447 & MAT $\alpha$ cdc17-1 mec1-1 trp1 \\
\hline TWY448 & MATa cdc17-1 mec2-1 his7 \\
\hline TWY449 & MAT $\alpha$ cdc17-1 mec3-1 ura1 ura3 his7 trp1 \\
\hline TWY450 & MATa cdc17-1 rad24-1 his7 leu2 trp1 \\
\hline TWY451 & MATa cdc28-1 ura1 ura3 his3 his7 \\
\hline TWY452 & MATa cdc28-1 mec1-1 his7 \\
\hline TWY453 & MATa cdc28-1 mec2-1 ura3 his7 \\
\hline TWY454 & MATa cdc28-1 mec3-1 ura1 his7 \\
\hline TWY455 & MATa cdc28-1 rad24-1 ura1 ura3 his7 \\
\hline TWY146 & $M A T \alpha$ cdc13-1 ura3 his 7 \\
\hline TWY148 & MAT $\alpha$ cdc13-1 mec2-1 ura3 his7 \\
\hline TWY158 & MAT $\alpha$ cdc13-1 mec1-1 ura3 his7 \\
\hline TWY159 & $M A T \alpha$ cdc13-1 mec3-1 ura3 his7 \\
\hline $\mathrm{KSS} 255^{\mathrm{c}}$ & MATa rad24-1 ura3 trp1 his3 leu2 lys2 \\
\hline$g 151-12 c^{c}$ & MATa rad53-1 ade2-1 ade1 arg4-17 lys1-1 his5-2 \\
\hline
\end{tabular}

Strains were generated in this study, except for the following:

${ }^{\text {a}}$ Weinert and Hartwell (1990).

bHartwell and Weinert (1989).

${ }^{c}$ KSS255 from K. Sitney and g151-12a from the Berkeley Stock Center are not congenic with A364a. 
Table 2. Phenotypes of checkpoint mutants

\begin{tabular}{llcccc}
\hline & & \multicolumn{4}{c}{ Phenotypes } \\
\cline { 3 - 6 } Strain $^{\mathrm{a}}$ & Allele & $\begin{array}{l}\text { cdc13 } \\
\text { arrest }^{\mathrm{b}}\end{array}$ & MMS $^{\mathrm{c}}$ & HU $^{\mathrm{c}}$ & $\mathrm{X}_{\text {-ray }}$ \\
\hline MEC $^{+}$ & & + & + & + & + \\
$\operatorname{mec1}$ & -1 & - & - & - & - \\
& $-3,-4,-6,-11$ & - & - & - & + \\
& -7 & - & - & \pm & + \\
& $-8,-10$ & - & - & \pm & - \\
$\operatorname{mec2}$ & $-2,-5,-9,-12$ & - & + & + & + \\
& $-1,-2,-3$ & - & - & - & - \\
$\operatorname{mec3}$ & -4 & - & + & - & - \\
$\operatorname{rad24}$ & -1 & - & - & \pm & - \\
$\operatorname{rad9}$ & $-10,-11,-12$ & - & - & + & - \\
& -13 & - & \pm & + & -
\end{tabular}

a Strains were derived from TWY146 MATa cdc13 ura3 his7, except for the rad24 mutant (TWY435) (see Table 1). Genes and alleles were assigned by complementation and allelism tests (see Materials and methods).

${ }^{b}$ The $c d c 13$-arrest phenotype measures arrest in $\mathrm{G}_{2}$ after DNA damage. Cells were grown to midlog in liquid culture at the permissive temperature, plated on agar plates, and shifted to the restrictive temperature of $36^{\circ} \mathrm{C}$. After $10-16 \mathrm{hr}$, plates were examined microscopically. Strains that had an intact checkpoint produced microcolonies that primarily contained either two or four buds, and produced strains with a defective checkpoint, mostly microcolonies that contained five buds or more.

'Sensitivity to MMS, HU, and X-rays was determined by comparing patches of cells replicated onto selective medium $(0.01 \%$ MMS, $0.1 \mathrm{M} \mathrm{HU}$ ), or complete medium (without drug), or after $\mathrm{x}$-irradiation. Alternatively, we determined the ability of single cells to form visible colonies when streaked on plates containing selective medium. mec3 and rad24 were consistently more HU sensitive than rad 9 mutants but less sensitive than mec1 and mec2 mutants. mec1-1, mec2-1, and mec3-1 are each UVsensitive (data not shown), as is rad24 (Eckardt-Schupp et al. 1987).

Table 3. Genetic mapping of mec1 and mec2

\begin{tabular}{llccc}
\hline Mutant & \multicolumn{1}{l}{ Cross $^{\mathrm{a}}$} & PD & NPD & T \\
\hline mec1 & $\frac{c d c 28 \text { mec1 }}{+\quad+}$ & 38 & 0 & 4 \\
& $\frac{c d c 28 \quad+}{+\quad \text { lys2 }}$ & 25 & 0 & 23 \\
& $\frac{m e c 1 \quad+}{+\quad \text { lys2 }}$ & 22 & 0 & 18 \\
mec2 & $\frac{\text { mec2-1 }}{\text { rad53-1 }}$ & 16 & 0 & 0 \\
& & & & \\
\hline
\end{tabular}

Conclusion: $1 . \underbrace{c d c 28 \rightarrow}_{4.8 \mathrm{cM}} \underbrace{m e c 1 \rightarrow l y s 2}_{22.5 \mathrm{cM}}$

2. mec2-1 and rad53-1 are allelic

aTo map mec1, diploids were analyzed that were either $c d c 28$ mec $1+1++$ lys 2 or $c d c 28$ mec $1+1++:: U R A 3$ lys 2 (contains a partial duplication of the MEC1 gene with the URA3 gene integrated at the MEC1 locus; $T$. Weinert, unpubl.) To map mec2-1, a diploid formed from mec2-1 and rad53-1 haploid parents was analyzed.
Table 4. Checkpoint mutants fail to arrest the cell cycle after $x$-irradiation

\begin{tabular}{lccc}
\hline Strain $^{\text {a }}$ & $\begin{array}{l}\text { Percent } \\
\text { lethality }\end{array}$ & $\begin{array}{l}\text { Percent } \\
\text { arrest }\end{array}$ & $\begin{array}{c}\text { Arrest } \\
\text { lethality }\end{array}$ \\
\hline$M E C^{+}$ & 49 & 42 & 0.82 \\
mec1-1 & 79 & 19 & 0.24 \\
mec2-1 & 68 & 22 & 0.32 \\
mec3-1 & 68 & 24 & 0.35 \\
rad24-1 & 69 & 11 & 0.16 \\
rad94 & 84 & 16 & 0.19 \\
\hline
\end{tabular}

The fraction of arrested cells/cell lethality at a low dose of $\mathrm{x}$-rays ( 2 krads) provides a convenient metric of cell cycle arrest (discussed in Materials and methods). Results are from a single experiment. Strains are $M E C^{+}$, TWY397; mec1-1, TWY158; mec2-1, TWY148; mec3-1, TWY159; rad24-1, TWY435; rad9, TWY398.

sponding $c d c-$ checkpoint double mutants for four phenotypes, including arrest morphology, first cycle arrest, cell viability, and maximum permissive temperature for colony formation (see Materials and methods). This strategy was used previously to characterize rad 9 and rad17 mutants.

All six checkpoint genes are required for arrest of cdc mutants in the $G_{2}$ phase with DNA damage

One class of $c d c$ mutants arrests in the $G_{2}$ phase after shift to the restrictive temperature and encodes gene products that are involved in DNA metabolism ( $c d c 9$, DNA ligase; $c d c 2$, DNA polymerse $\gamma ; c d c 17$ at $34^{\circ} \mathrm{C}$, DNA polymerase $\alpha$; and $c d c 13$, function unknown; see introductory section). Each of the corresponding $c d c-$ checkpoint double mutants showed some defect in cellcycle arrest (although for some mutants the arrest defect is relatively small), and all double mutants died more rapidly at the restrictive temperature compared with the $c d c$ single mutants (Table 5). Each $c d c$-checkpoint double mutant also showed an altered maximum permissive temperature compared with the $c d c$ strain. For $c d c 2$, $c d c 17$, and $c d c 9$ the maximum permissive temperature was lower in the $c d c$-checkpoint double mutant; mutant cells grown at intermediate temperatures are limited for the function of these DNA replication enzymes and likely require a delay at the checkpoint to complete replication before mitosis and to remain viable. The maximum permissive temperature is higher in the cdc13-checkpoint double mutants, though most cells formed at the higher temperature were inviable (for discussion, see Weinert and Hartwell 1993). The phenotypes for this DNA replication-defective class of $c d c-$ checkpoint double mutants are similar to those of the corresponding $c d c$ rad 9 and $c d c$ rad17 double mutants. The results indicate that all six checkpoint genes are required for arrest in the $G_{2}$ phase after DNA damage resulting from defects in DNA replication enzymes.

Though we consistently observed a qualitative correlation between the increased cell death and a defect in cell-cycle arrest, we do not always see a quantitative 
correlation between the extent of cell death and of the defect in cell-cycle arrest (see Table 5; e.g., cf. cdc13 mec1 and cdc13 mec2; or cdc9 mec1 and cdc9 rad24). This suggests that the cause of cell death may not be attributable solely to a defect in cell cycle arrest. Some cell death may be due instead to defects in DNA repair or to defects in gene product interactions between the checkpoint and DNA replication proteins.

\section{MECl and MEC2 are also essential for arrest in $S$ phase}

Three results indicate that $m e c 1$ and mec2 mutants have a defect in S-phase arrest when DNA replication is blocked. First, $c d c 8 m e c 1$ and $c d c 8$ mec2 double mutants were synthetically lethal; after sporulation of appropriate diploids we were unable to recover any viable double mutants (from $c d c 8 /+$ mec1/+ or cdc8/+ mec2/ + diploids, analyzing 22 and 25 tetrads with $66 \%$ and $70 \%$ spore viability, respectively|. We infer that the double mutants were formed during meiosis but were inviable because we did recover the three other expected genotypes $\left(c d c 8\right.$, mec1, and $\left.C D C^{+} M E C^{+}\right)$at frequencies expected for unlinked genes $(c d c 8$, mec1, and mec2 are on CHRX, CHRII, and CHR XV, respectively). Because the double mutants were apparently inviable under conditions where both single mutants are viable, $c d c 8 m e c 1$ and $c d c 8 m e c 2$ mutants are synthetically lethal. $c d c 8$ mutants at $23^{\circ} \mathrm{C}$ are partially defective for DNA replication (see Weinert and Hartwell 1993 and references therein), so $c d c 8$ spores germinated at $23^{\circ} \mathrm{C}$ might be expected to experience an S-phase delay and therefore require $M E C 1$ and $M E C 2$ for that delay and for cell viability.

Second, cdc17 mec1 mutants died more rapidly than did $c d c 17 \mathrm{MEC}^{+}$mutants at the high temperature $\left(38^{\circ} \mathrm{C}\right)$ that causes $c d c 17$ single mutants to arrest in $\mathrm{S}$ phase (Table 5). The cdc17 mec1 mutant cells at $38^{\circ} \mathrm{C}$ also displayed a higher frequency of abnormal microtubule morphologies than did $c d c 17$ strains, suggesting that cdc17 mec1 cells fail to arrest under conditions where cdc17 MEC ${ }^{+}$cells do arrest (data not shown). However, the interpretation of the $c d c 17$ mec1 phenotypes is complicated because of the ambiguous phenotypes of other cdc17-checkpoint double mutants. For example, both cdc17 mec2 and $c d c 17$ mec3 strains showed a mild cellcycle arrest defect at $38^{\circ} \mathrm{C}$, yet the cell viability of both strains was comparable with that of the $c d c 17 M E C^{+}$ strain. By other criteria (e.g., interaction with $c d c 8$, response to $\mathrm{HU}$ / mec2 mutants are S-phase arrest defective, whereas mec3 mutants are not. The analysis of mec2 may also be complicated by its temperature sensitivity for growth (in a $C D C^{+}$background; see Table 5). The basis for this variability of phenotypes in some of the $c d c 17-$ checkpoint mutants at $38^{\circ} \mathrm{C}$ is unknown.

The third and most dramatic result that indicates an S-phase arrest defect in mec1 and mec2 mutants was their response to incubation with HU. HU-treated mec1 and mec2 mutant cells failed to cell-cycle arrest and died rapidly, whereas wild-type cells arrested and remained viable (Table 6; Fig. 2). From their DNA and tubulin morphologies (Fig. 2; data not shown), mec1 and mec2 mutants appeared to attempt and even complete mitosis in the presence of $\mathrm{HU}$. The low viability of HU-treated mec1 and mec2 cells may be attributable to entry into mitosis of mutant cells under conditions where $M E C^{+}$ cells remain arrested. Again, other contributions to cell inviability (e.g., defects in DNA repair, defective gene product interactions) cannot be ruled out at present.

\section{Interactions of checkpoint mutants with other cdc} mutants

Checkpoint mutations did not affect the phenotypes of $c d c$ mutants that arrest in $\mathrm{G}_{1}(c d c 28), \mathrm{G}_{1}-\mathrm{S}(c d c 7), \mathrm{G}_{2}-\mathrm{M}$ (cdc16), or postanaphase (cdc15) after shift to the restrictive temperature (Table 5). By the criteria of interaction with $C D C$ genes, the role of the checkpoint genes appears restricted to the $S$ and/or $G_{2}$ phase of the cell cycle and to respond to incomplete DNA replication or DNA damage.

The analysis of $c d c 6-$ checkpoint mutants gave results that were less dramatic and more difficult to interpret. For example, from their nuclear morphology cdc6 mec1 mutants appeared arrest-defective compared to the $c d c 6$ strains (most double mutant cells did not arrest as largebudded cells with an undivided nucleus|, however cell viabilities were similar in the two strains. Although the strongest interactions appeared between $c d c 6$ and mec3, there may be some interaction with the other checkpoint mutants as well (including rads and rad17, Weinert and Hartwell 1993), because all double mutant combinations have a lower maximum permissive temperature than the $c d c 6$ strain. The interaction of $C D C 6$ and checkpoint genes requires additional studies.

\section{Discussion}

Six checkpoint genes are required for arrest in the $G_{2}$ phase after DNA damage

We have now identified and characterized mutants in six checkpoint genes, RAD9, RAD17, RAD24, MEC1, MEC2 (RAD53), and MEC3. All are essential for the DNA damaged-induced cell-cycle arrest in the $G_{2}$ phase. This conclusion is based on several observations. First, all checkpoint mutants were defective for cell-cycle arrest following X-irradiation (Table 4); those tested also failed to cell-cycle arrest after UV-irradiation (rad 9 and rad17; Weinert and Hartwell 1993|, and all of the mutants are also sensitive to DNA-damaging agents (X-ray, UV, and MMS|. The sensitivity to DNA-damaging agents may be attributable solely to a failure to cell- cycle arrest, though we have not ruled out an additional direct role in DNA repair.

Second, all of the checkpoint genes show a striking interaction with a class of $C D C$ genes that function in DNA replication. Each of the $C D C$ genes in this class (CDC2, $C D C 9, C D C 13$, and $C D C 17)$ encode proteins involved in DNA metabolism (see introductory section), 
Table 5. Role of checkpoint genes in arrest of cdc mutants

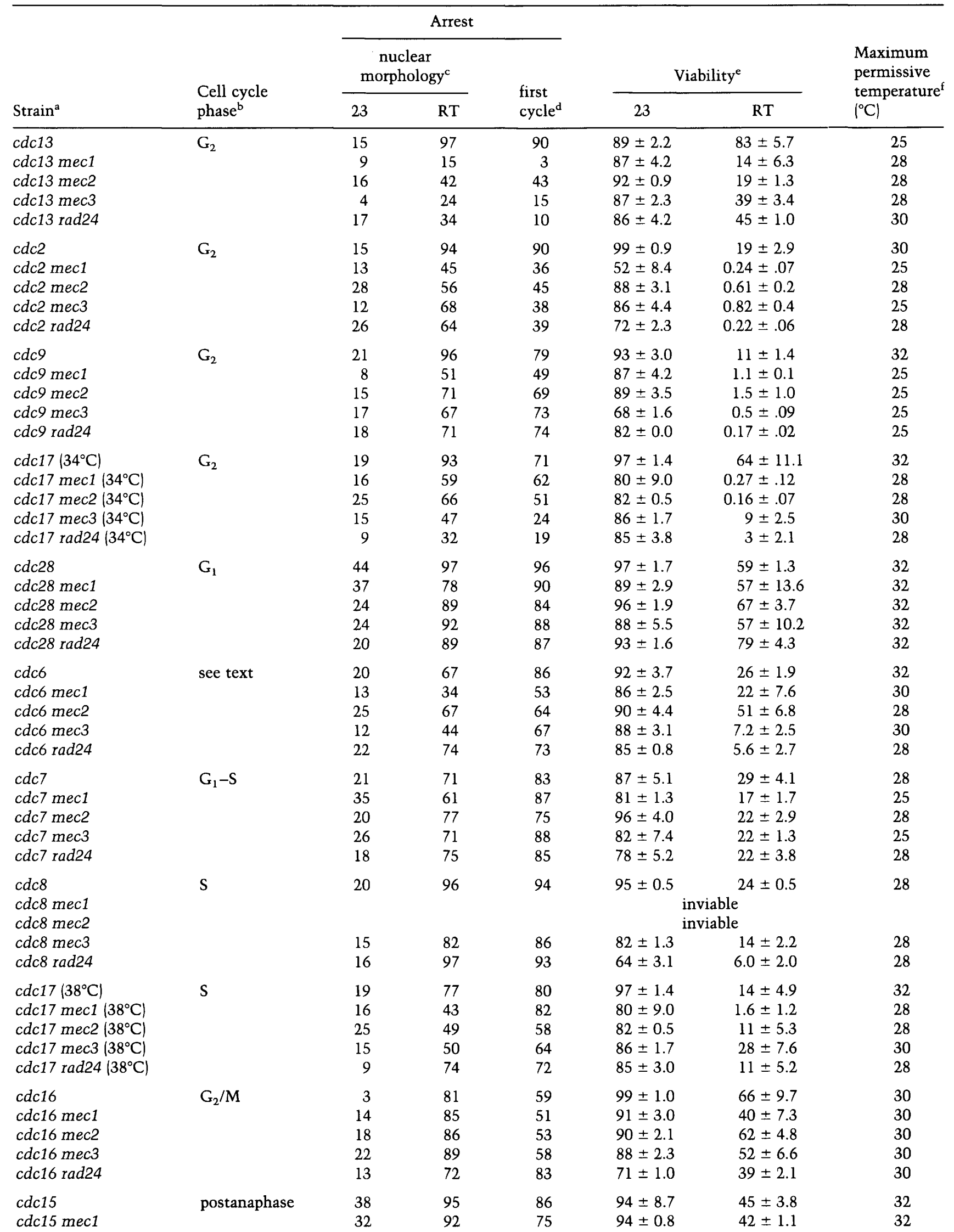

(Table 5 continued on facing page) 
Table 5. (Continued)

\begin{tabular}{|c|c|c|c|c|c|c|c|}
\hline \multirow[b]{3}{*}{ Strain $^{a}$} & \multirow{3}{*}{$\begin{array}{l}\text { Cell cycle } \\
\text { phase }^{\text {b }}\end{array}$} & \multicolumn{3}{|c|}{ Arrest } & & & \multirow{3}{*}{$\begin{array}{l}\text { Maximum } \\
\text { permissive } \\
\text { temperature } \\
\left({ }^{\circ} \mathrm{C}\right)\end{array}$} \\
\hline & & \multicolumn{2}{|c|}{$\begin{array}{c}\text { nuclear } \\
\text { morphology }\end{array}$} & \multirow{2}{*}{$\begin{array}{l}\text { first } \\
\text { cycle }^{d}\end{array}$} & \multicolumn{2}{|c|}{ Viability $^{e}$} & \\
\hline & & 23 & RT & & 23 & $\mathrm{RT}$ & \\
\hline$c d c 15$ mec2 & & 38 & 87 & 87 & $91 \pm 6.6$ & $67 \pm 11.5$ & 32 \\
\hline cdc15 mec3 & & 22 & 92 & 85 & $88 \pm 6.1$ & $53 \pm 6.3$ & 32 \\
\hline cdc15 rad24 & & 11 & 70 & 98 & $85 \pm 2.9$ & $40 \pm 4.9$ & 32 \\
\hline$M E C^{+}$ & asynchronous & 22 & 28 & 15 & $97 \pm 1.8$ & $93 \pm 2.7$ & 36 \\
\hline mec1 & asynchronous & 16 & 19 & 40 & $93 \pm 2.1$ & $92 \pm 4.2$ & 36 \\
\hline mec2 & asynchronous & 38 & 33 & 18 & $79 \pm 5.7$ & $68 \pm 5.9$ & 32 \\
\hline mec3 & asynchronous & 10 & 12 & 25 & $83 \pm 4.9$ & $83 \pm 4.9$ & 36 \\
\hline rad24 & asynchronous & 20 & 22 & 16 & $90 \pm 5.3$ & $86 \pm 1.3$ & 36 \\
\hline
\end{tabular}

atrains are shown in Table 1. Restrictive temperature $(\mathrm{RT})$ for $c d c$ mutations was $36^{\circ} \mathrm{C}$, except as noted.

${ }^{b}$ Conclusions from these and previously published observations.

cPercentage of cells with a large bud and undivided nucleus, except $c d c 28$ (unbudded) and $c d c 15$ (large budded with divided nucleus).

${ }^{\mathrm{d}}$ Percentage of microcolonies that contain either two or four buds (microcolony assay), except for cdc28 (one or two buds).

eMean value from three to six cultures; standard deviation shown.

${ }^{\mathrm{f}}$ Maximum permissive temperature of colony formation.

and DNA replication in the corresponding temperaturesensitive mutants at the restrictive temperature is either incomplete or complete with errors /causing arrest in late $S$ or $G_{2}$ phase, respectively|. Each of these four $c d c$ DNA replication-defective mutants arrested in the $G_{2}$ phase at the restrictive temperature, whereas each of the corresponding $c d c$-checkpoint double mutants failed to arrest and died rapidly. Unrepaired DNA lesions in these $c d c$ mutants at the restrictive temperature probably activate the checkpoint, and cell death in the checkpoint mutants occurs either because of cell division with dam-

Table 6. Inhibition of DNA replication by hydroxyurea confirms the $S$-phase arrest defect in $\mathrm{mecl}$ and mec2 mutants

\begin{tabular}{lclc}
\hline & $\begin{array}{l}\text { Nuclear } \\
\text { morphology } \\
(-\mathrm{HU} /+\mathrm{HU})\end{array}$ & $\begin{array}{l}\text { Viability } \\
(-\mathrm{HU} /+\mathrm{HU})\end{array}$ & $\begin{array}{l}\text { Spindle }^{\mathrm{c}} \\
\text { (\% normal } \\
\text { in HU) }\end{array}$ \\
\hline Strain $^{\mathrm{a}}$ & $27 / 91$ & $96 \pm 1.2 / 91 \pm 2.3$ & 97 \\
meC $^{+}$ & $20 / 27$ & $95 \pm 3.5 / 0.2 \pm 0.07$ & 3 \\
mec2 & $30 / 69$ & $93 \pm 3.6 / 0.5 \pm 0.07$ & 38 \\
mec3 & $16 / 89$ & $85 \pm 2.3 / 63 \pm 2.9$ & 97 \\
rad24 & $18 / 74$ & $83 \pm 3.8 / 79 \pm 1.0$ & 95 \\
\hline
\end{tabular}

aStrains: $M E C^{+}$, TWY397; mec1-1, TWY308;mec2-1, TWY312; mec3-1, TWY316; rad24-1, TWY399.

${ }^{\mathrm{b}}$ Cells were incubated with $0.2 \mathrm{M}$ hydroxyurea in liquid media at $30^{\circ} \mathrm{C}$ for $4 \mathrm{hr}$ and analyzed for cell viability and morphology. Arrested cells are large budded and have an undivided nucleus. 'The spindle morphology observed specifically in large-budded cells is presented. Normal short spindles seen in HU-arrested wild-type cells were at the neck of the bud. Abnormal spindles were clearly neither short nor elongated, though details of their abnormality were not always easily identified (abnormalities are more easily seen in larger diploid cells; see Fig. 2). The microtubule phenotypes of unbudded cells were normal. Few large-budded cells with an elongated spindle and bipolar nucleus were observed. aged chromosomes, defects in DNA repair, defects in gene product interactions, or a combination of these. We cannot determine the exact cause(s) of cell death in the $c d c$-checkpoint double mutants from these studies.

Our results suggest that any type of DNA lesion (generated by MMS-, UV-, or X-irradiation or by defects in DNA replication/ causes an arrest that requires all six checkpoint genes. We have no evidence that some checkpoint genes are required for arrest due to specific types of DNA lesions, although if such mutants do exist, we may not have detected them because our mutant isolation strategies used only radiation- or $c d c 13$ - induced DNA lesions. Some alleles of mec1 are more resistant to DNA-damaging agents than are other alleles (Table 2), a result that could suggest lesion-specific detection by different alleles of MEC1. However, these different phenotypes may simply reflect different quantitative levels of function and not qualitatively different functions. This question needs to be examined further. In sum, we favor the idea that all of these genes play a role in signal transduction once some form of DNA damage has been generated.

\section{$\mathrm{MECl}$ and $\mathrm{MEC} 2$ define distinct $S$ - and $G_{2}$-phase pathways of the mitotic checkpoint}

Mutants in the MEC1 and MEC2 genes were identified by their defects in the $G_{2}$ pathway but, when analyzed, proved to be defective for an S-phase pathway as well. This conclusion is based on the following observations: mec1 and mec2 mutants treated with HU failed to arrest and were inviable; mec1 and mec2 were synthetically lethal with $c d c 8$; and $c d c 17$ mec1 failed to arrest and died more rapidly than $c d c 17$ mutants at the high temperature $\left(38^{\circ} \mathrm{C}\right)$ at which $c d c 17$ cells arrest in S phase. From the nuclear morphology of HU-treated cells, mec1 and mec2 mutant cells with incompletely replicated DNA appeared to enter (and even complete) mitosis. Mi- 


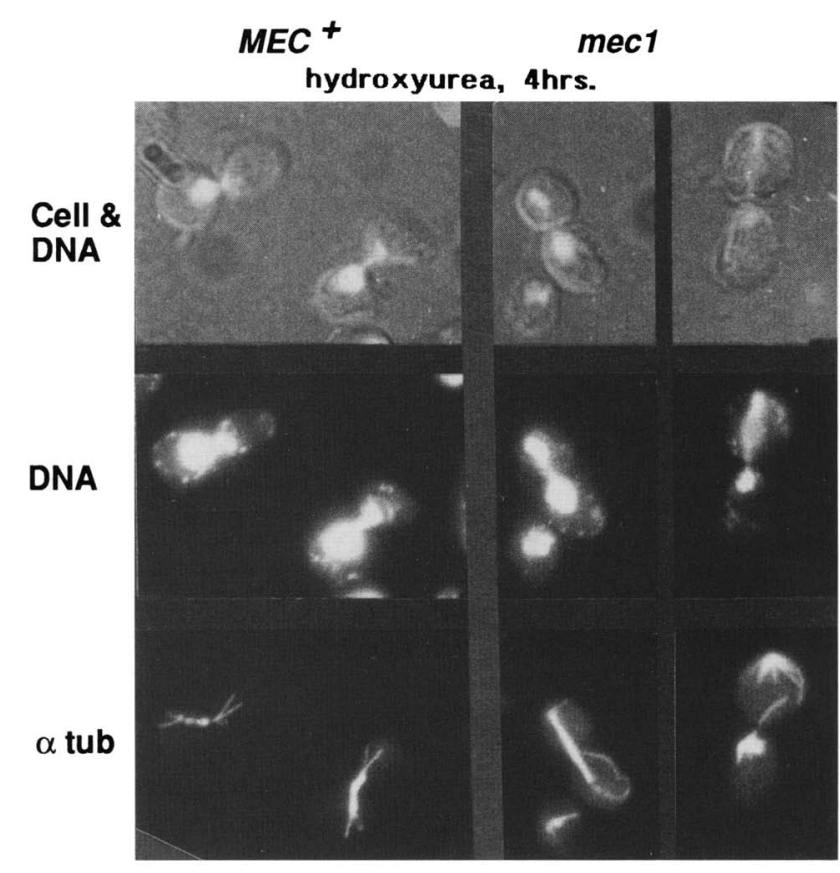

Figure 2. Inhibition of DNA replication by incubation of cells with HU causes cell-cycle arrest of $\mathrm{MEC}^{+}$cells but not mec1 cells. Diploid cells (TWY123, $\mathrm{MEC}^{+} / \mathrm{MEC}^{+}$; TWY162 mec1) mec1) were treated for $4 \mathrm{hr}$ with $\mathrm{HU}$ at $30^{\circ} \mathrm{C}$, fixed, and stained for nuclear and microtubule morphologies. (Top) Cell morphology, using Nomarski optics, and nuclear morphology simultaneously; (middle) nuclear morphology alone; (bottom) microtubule morphology.

tosis with unreplicated DNA has been observed in mammalian cells treated with both HU (to block DNA replication) and with caffeine (to override the checkpoint) (described as the MUG phenotype-mitosis with unreplicated genome; Brinkley et al. 1988.). In addition, several fission yeast genes function in an S-phase pathway analogous to that mediated by $M E C 1$ and $M E C 2$ (Enoch and Nurse 1990; Al-Khodairy and Carr 1992; Enoch et al. 1992; Jimenez et al. 1992; Rowley et al. 1992b; for review, see Murray 1993). The RCC1 gene in mammalian cells (Nishimoto et al. 1978) and in fission yeast (Matsumoto and Beach 1991), and the bimE gene in filamentous fungi (Osmani et al. 1988; 1991; for review, see Dasso 1993.) are also essential for an S-phase pathway in those organisms. The existence of an S-phase pathway appears to be universal among eukaryotic cells.

\section{The dependence of mitosis on DNA replication is enforced by an $S$ - and a $G_{2}$-phase pathway}

The model in Figure 3 summarizes one view of the relationship between the six checkpoint genes and the cell cycle in budding yeast. [The EMS-induced checkpoint mutations are uncharacterized as to their molecular lesions, so except for the rad9 mutation, which is a null, these mutants may retain partial function. We believe

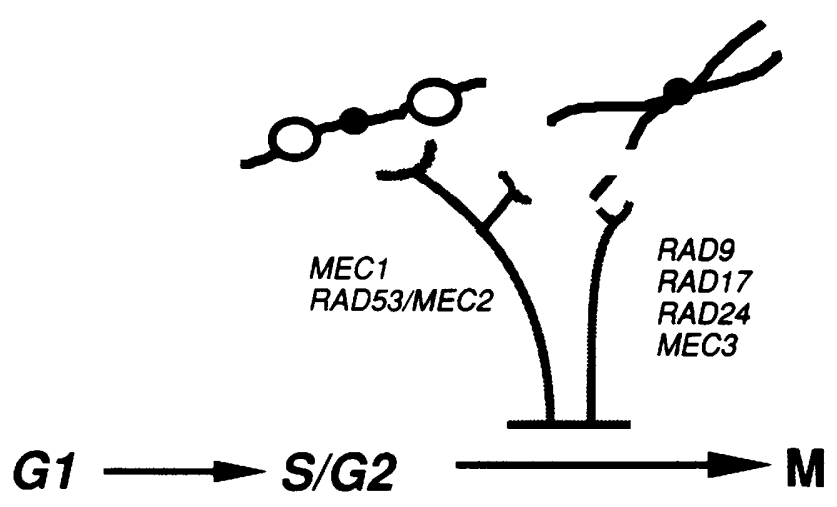

Figure 3. Summary of the roles of the checkpoint genes in the S- and $\mathrm{G}_{2}$-phase pathways in checkpoint control. (Top) Partially replicated chromosomes with two replication bubbles and centromere, and two fully duplicated sister chromatids, one of which has a break.

that the general conclusions on phase specificity are correct because null mutants of rad17, rad24, and mec3 have phenotypes similar to those of the mutants studied here (D. Lydall and T. Weinert, unpubl.)]. We imagine that the checkpoint genes have some role(s) in the signal transduction process. It is unlikely that any of these genes represent the target of checkpoint control for the following reason: We anticipate that the target will be a gene(s) essential for mitosis, and a checkpoint-defective mutant allele in that gene might be dominant. This expectation derives from mutations in fission yeast in the $C D C 2$ gene $(c d c 2-3 w)$, which are dominant and have a checkpoint defect (Enoch and Nurse 1990). All of the checkpoint mutant alleles that we have characterized in budding yeast are recessive (Table 2; Weinert and Hartwell 1988, 1993).

\section{Possible mechanistic relationships between $S$} and $G_{2}$ pathways

Why does the cell employ two DNA-sensitive mechanisms to ensure chromosome integrity before mitosis? Conceptually, the two may play fundamentally different roles (Enoch and Nurse 1991; Li and Deschaies 1993; see Murray 1993). We imagine the $G_{2}$ pathway has a conceptually simpler function where DNA lesions trigger arrest in $\mathrm{G}_{2}$, and the pathway constitutes an extrinsic control to mitosis normally not essential for viability. The $G_{2}$ pathway ensures that damage generated either spontaneously during replication or by specific environmental insults is repaired before mitosis. This control is analogous to that of the DNA damage-sensitive recA-dependent response in bacteria.

The S-phase pathway may be more complex and may be intrinsic to DNA replication itself, perhaps by ensuring that the time for DNA replication is sufficient. How does the cell sense incomplete DNA replication? The cell may detect some feature of a replication fork. Specific proteins may serve both in DNA replication and in cell-cycle control. In this regard, the role of $C D C 6$ in cell 
division may be of interest. Recently, a CDC6 homolog in fission yeast, $c d c 18^{+}$, was reported to have a checkpoint function, acting as a positive regulator of DNA replication and as a negative regulator of mitosis (Kelly et al. 1993). In budding yeast genetic evidence also suggests CDC6 may function both in the initiation of DNA replication (Hartwell 1976; Hogan and Koshland 1992) as well as an inhibitor of mitosis (Bueno and Russell 1992). The mitotic arrest caused by overexpression of $C D C 6$ does not require the $R A D 9$ gene (Bueno and Russell 1992). We have seen weak interactions between $C D C 6$ and the checkpoint genes (Table 5), and the meaning of these possible interactions remains to be established.

A model of the mitotic checkpoint must account for why $M E C 1$ and $M E C 2$ are required in both the $\mathrm{S}$ and $\mathrm{G}_{2}$ pathways, whereas the other four checkpoint genes function solely in the $G_{2}$ pathway. We consider two possibilities. First, the signal in the $S$ and $G_{2}$ phases may be processed by distinct pathways that subsequently converge on the $M E C 1 / M E C 2$ function and then on the target. This model predicts the existence of genes that act in an as-yet-unidentified and distinct S-phase pathway (see Murray 1993). In a second model, MEC1/MEC2 function during $S$ phase, and their function in $S$ phase is required for the subsequent function of the $G_{2}$ pathway. This model posits that $M E C 1$ and $M E C 2$ act before the $\mathrm{G}_{2}$ pathway genes. If this model is correct, $M E C 1 / M E C 2$ must have a constitutive role in the cell cycle because previous results showed that when cells in the $G_{2}$ phase were irradiated, the $G_{2}$ pathway was activated and cells arrested in $\mathrm{G}_{2}$ (Weinert and Hartwell 1988, 1993). At present, we have no observations that distinguish between the two possibilities.

\section{Comparison of the mitotic checkpoints in fission and budding yeasts}

The general organization of the checkpoint that orders DNA replication and mitosis appears similar in fission and budding yeast (for review, $\mathrm{Li}$ and Deschaies 1993; Murray 1993). Both yeasts have genes that function specifically in the $G_{2}$ pathway in response to DNA damage: Four genes in budding yeast (see Fig. 3) and at least two genes in fission yeast, $\operatorname{chk} 1^{+}$(Walworth et al. 1993) and wee $1^{+}$(Rowley et al. 1992a; but see Barbet and Carr 1993.). Both yeasts have genes that function in both the S- and $\mathrm{G}_{2}$-phase pathways: $M E C 1$ and $M E C 2$ in budding yeast and at least 11 genes in fission yeast (see Murray 1993). The genetic analyses in both yeasts appear incomplete so yet more checkpoint genes will likely be identified: Whether these genes from the two yeasts share sequence similarities and/or molecular functions awaits their molecular analysis.

\section{Target of the mitotic checkpoint}

A possible target of checkpoint regulation is p34 ${ }^{C D C 2 / C D C 28}$ (Nurse 1990). Support for this hypothesis comes from experiments in fission yeast showing that mutants in $c d c 2^{+}$and its regulators $\left(c d c 25^{+}\right.$and wee $\left.1^{+}\right)$ have checkpoint defects. Another possible direct link between the checkpoint genes and $c d c 2^{+}$in fission yeast was reported recently in the genetic suppression of a cdc2 mutation by the checkpoint gene $\operatorname{chk} 1^{+}$(Walworth et al. 1993). In budding yeast it is unclear what interaction, if any, exists between checkpoint genes and $C D C 28$, the $c d c 2^{+}$homolog. For example, the same cdc2 mutants that have a checkpoint defect in fission yeast have no detectable phenotype in budding yeast (Amon et al. 1992; Sorger and Murray 1992; for review, see Murray 1993; Weinert and Lydall 1993). We have also not yet detected genetic interactions between CDC28 and the budding yeast checkpoint genes (see Table 4; D. Lydall and T.A. Weinert, unpubl.). The identity of the essential mitotic controls and how it is regulated by checkpoint genes remains a central unanswered question.

\section{Limitations of the checkpoint screen}

The screen based on the $c d c 13$ arrest phenotype has limitations indicating that additional checkpoint mutants might be identified using other criteria. The screen was apparently biased in identifying some but not all checkpoint genes; we recovered multiple alleles of mec1, mec2, and rad 9 but only a single allele of mec3 and no alleles of rad17 and rad24. Some checkpoint mutants may have been under-represented in our screen because they were not sufficiently lethal in combination with cdc13. For example, $c d c 13 \mathrm{rad} 24, c d c 13 \mathrm{mec} 3$, as well as $c d c 13$ rad17, retain greater viability after $4 \mathrm{hr}$ at the restrictive temperature than do the other three $c d c 13$ checkpoint double mutants (Table 5; Weinert and Hartwell 1993). In addition, our screen may be limited to genes involved in recognizing a subset of possible DNA lesions |cdc13-defective cells accumulate singlestranded DNA at the restrictive temperature). We note, however, that the lesions in cdc13-defective cells must eventually share a common feature with radiation-induced lesions because all checkpoint mutants are radiation sensitive as well. Additional searches for checkpoint mutants might exploit the lethality of other $c d c-$ checkpoint double mutants at the restrictive temperature for the $c d c$ mutation (Table 5), or the observation that all six $c d c 13$-checkpoint double mutants have a higher maximum permissive temperature than do cdc13 single mutants.

The use of synthetic lethality to identify checkpoints and checkpoint genes

The checkpoint mutant isolation strategy used here relied on the following simple hypothesis: A checkpoint detects cellular defects and arrests cell division to provide the cell time for repair. Cell lethality results in checkpoint-defective cells when cell division occurs without repair of damage. In this study we introduced DNA damage by using a temperature-sensitive mutation (cdc13) and identified checkpoint mutants because they died rapidly and continued cell division despite the 
damage. A conceptually similar approach was used to isolate mutants in the S-phase pathway in fission yeast because they failed to arrest and died rapidly when treated with HU (hus mutants; Enoch et al. 1992). Similarly, mutants that identify a checkpoint responsive to microtubule function or assembly (MAD and $B U B$ genes) were identified from their failure to arrest and their low viability when treated with the microtubule poison benomyl (Hoyt et al. 1992; Li and Murray 1992). The checkpoint mutants identified here exhibited unselected phenotypes (e.g., radiation sensitivity) that provide further evidence for their role in checkpoint function. Similarly, the hus, mad, and bub mutants exhibit unselected phenotypes consistent with their roles in a checkpoint function (Hoyt et al. 1991; Li and Murray 1991; Enoch et al. 1992; also see Neff and Burke 1992).

\section{Materials and methods \\ Strains and genetic methods}

All strains are congenic with A364a, except as noted in Table 1. The rad24-1 mutation was introduced into A364a by backcrossing the original rad24-1 mutation (from KSS255; Table 1) to an A364a parental strain six times. Yeast media and genetic methods were standard (Sherman et al. 1974). Cell-cycle studies were done with cells grown to midlog stage $\left(2 \times 10^{6}\right.$ to $\left.5 \times 10^{6} / \mathrm{ml}\right)$ in complete medium, except where noted.

\section{Radiation and drug sensitivities}

$\mathrm{X}$-irradiation of cells was performed by use of a Machlett OEG600 tube set at $50 \mathrm{kV}, 20 \mathrm{~mA}$, which delivered $106 \mathrm{rad} / \mathrm{sec}$, and UV-irradiation was delivered by use of a Stratalinker 1800. Qualitative UV-and X-ray sensitivities were determined by irradiating replicas of patches of cells two times, once at the time of replica plating and a second time $8-16 \mathrm{hr}$ later. Dose of radiation: X-rays, $8 \mathrm{krads}$; UV, $80 \mathrm{~J} / \mathrm{m}^{2}$. Strain survival was determined after incubation for $2-3$ days at $23^{\circ} \mathrm{C}$.

For drug sensitivites, patches of cells were replica plated on medium containing $0.01 \%$ of MMS (Sigma M-4016) or $0.1 \mathrm{M} \mathrm{HU}$ (Sigma H-8627). To determine MMS sensitivity, patches of cells were replica plated and immediately replica plated a second time (double-replicas) to MMS-containing solid medium. This procedure effectively dilutes the number of cells transferred and improved the discrimination of $M^{\prime} S^{s}$ and $M M S^{x}$ strains. We also monitored the ability of single cells to form visible colonies on solid medium containing either MMS or HU. The results from these qualitative tests of drug sensitivity varied with temperature and cell ploidy; we found that the most reproducible results were obtained using haploid strains at $23^{\circ} \mathrm{C}$ or diploid strains at $30^{\circ} \mathrm{C}$ (in $C D C^{+}$strains).

\section{Mutant isolation}

A cdc13 RAD strain (TWY146; MATa cdc13 ura3 his7 CAN1) was mutagenized with EMS to $\sim 50 \%$ viability, a dose that increased the frequency of point mutations $\sim 230$-fold (the frequency of canavanine resistance increased from $6 \times 10^{-6}$ to $\left.1.4 \times 10^{-3}\right)$. Mutagenized cells were grown to single colonies on solid medium at $23^{\circ} \mathrm{C}$, the permissive temperature for $c d c 13$. Each colony represented a potential independent mutant.
The screen for checkpoint mutants involved two steps. First we screened individual colonies for cell viability after incubation at the restrictive temperature (rapid death screen). Colonies were double replica plated (to reduce the number of cells transferred; see above) and subjected to a temperature upshift-downshift regime; $6 \mathrm{hr}$ at $36^{\circ} \mathrm{C}$, then $23^{\circ} \mathrm{C}$ overnight, followed by the same regime the following day. This procedure effectively squares the difference in cell survival between rapidly dying strains and the $c d c 13$ control strains. After a subsequent 2- to 3-day incubation at $23^{\circ} \mathrm{C}$, growth of each colony was compared with that of a $c d c 13$ strain, a $c d c 13$ rad9 strain, as well as with the mutant colony incubated only at $23^{\circ} \mathrm{C}$. We showed that cdc13 cells survive this temperature shift regime, whereas $c d c 13$ rad 9 cells do not. Strains that died rapidly were retested for their rapid death phenotype, and candidates were then tested for their cell-cycle arrest phenotype. All strains with the rapid death phenotype were also screened qualitatively for X-ray sensitivity, although this was not a necessary criterium for a checkpoint mutant.

Strains that exhibited a rapid death phenotype were screened individually for microcolony formation at the restrictive temperature. Cells from each strain were resuspended in liquid culture, grown for several generations at the permissive temperature, sonicated, plated on agar plates, and incubated at the restrictive temperature $\left(36^{\circ} \mathrm{C}\right)$. After $8-16 \mathrm{hr}$, the morphology of microcolonies arising from single cells was examined microscopically, and strains were characterized as arrested (forming microcolonies containing mostly two and four buds) or notarrested (forming microcolonies containing greater than four buds; see Fig. 1A,B).

\section{Genetic analysis of checkpoint mutants}

The checkpoint mutants were crossed to MATa $c d c 13$ and sporulated, and haploid segregants were tested for single gene segregation of mutant phenotypes. The $c d c 13$ arrest phenotype and the rapid death phenotypes cosegregated where tested. The $c d c 13$ arrest phenotype was used initially to follow all checkpoint mutations in crosses and to test for complementation because some alleles were not sensitive to DNA-damaging agents (see Table 2). We isolated appropriate MATa cdc13checkpoint double mutants for complementation and allelism tests. Initial gene assignments were made from complementation tests and were verified by allelism tests; all mutants showed tight linkage to the prototype allele from its complementation group /though spore viability was low in some strains). The strongest mutant alleles were selected for further study (mec1-1, mec2-1, and mec3-1, as well as rad24-1; obtained from K. Sitney and B. Mortimer, University of California, Berkeleyl.

\section{Cell-cycle arrest after $X$-irradiation}

Cells were grown in rich liquid medium to midlog phase, sonicated, plated on solid medium, and treated with a low dose of $\mathrm{X}$-rays ( $2 \mathrm{krad}$ ) that generates a few double-strand breaks per cell (see Weinert and Hartwell 1988). After incubation of irradiated cells for 8-10 hr, cell-cycle arrest was determined from the morphology of microcolonies and from the cell inviability (determined $24 \mathrm{hr}$ after irradiation). The ratio of percent arrested cells (microcolonies with either a large-budded cell or with two adjacent large-budded cells) divided by the percent of inviable cells provides a metric of the efficiency of cell cycle arrest. For wildtype cells this metric approaches 1.0 because essentially all cells with unrepairable DNA breaks die and arrest in the $G_{2}$ phase; 
haploid cells in the $G_{1}$ or postanaphase stages when $\mathrm{X}$-irradiated cannot repair the DNA double-strand breaks, arrest in the next $\mathrm{G}_{2}$ phase, and die as large-budded and two adjacent large-budded cells, respectively. Wild-type cells that can repair the doublestrand break ( $\mathrm{S}$ - and $\mathrm{G}_{2}$-phase cells) form large microcolonies that are not counted. In contrast, checkpoint mutant cells that die after X-irradiation do not usually arrest immediately, rather they continue to divide for a few generations. Therefore, in checkpoint mutants, the ratio of arrested to inviable cells is $<<1.0$ and typically $<0.3$. Cell death of irradiated cells is likely attributable to unrepaired DNA damage though may not be due solely to the defect in cell-cycle arrest, as discussed in the text.

\section{Cell-cycle response to $\mathrm{HU}$}

HU inhibits DNA replication by depleting cells of dNTP precursors, presumably by inhibiting ribonucleotide reductase, and causes wild-type cells to arrest cell division in S phase. Cells were grown to midlog in liquid medium and then incubated for $4 \mathrm{hr}$ with $0.2 \mathrm{M} \mathrm{HU}$. HU was removed by washing cells twice with water and plated to determine cell viability, or fixed with $70 \%$ ethanol for $1 \mathrm{hr}$ and stained with 4,6-diamino-2-phenyl indole (DAPI) for analysis of cell and nuclear morphology. To determine microtubule morphology, cells were fixed with freshly prepared paraformaldehyde and stained with DAPI and anti-tubulin antibodies (Pringle et al. 1989). For each strain, at least 100 cells was examined by fluorescence microscopy.

We found that with $\mathrm{HU}$ a first cycle arrest assay was not a particularly informative phenotype. HU-resistant cells plated on medium containing $\mathrm{HU}$ arrested in the first cycle (forming microcolonies of large-budded and two adjacent large-budded cells) and eventually recovered to resume cell division. HU. sensitive cells (mec1 and mec2) plated on medium containing $\mathrm{HU}$ also appeared to arrest in the first cycle as large-budded cells but never resumed cell division. Analysis of nuclear morphology provides an explanation for why mec1 and mec2 mutants fail to recover: HU-sensitive cells appear to attempt mitosis before completion of DNA replication, die, and therefore do not resume cell division like HU-resistant cells.

\section{Analysis of cdc-checkpoint double mutants}

$c d c$ mutants that arrest in specific stages of the cell cycle were crossed to checkpoint mutants and $c d c-c h e c k p o i n t$ double mutants were isolated (Table 1). The interactions of checkpoint and $C D C$ genes were assessed by comparing four phenotypes of the $c d c$ and respective $c d c$-checkpoint double mutants. After shift to the restrictive temperature for $4 \mathrm{hr}$, we determined the cell and nuclear morphology, cell viability, and whether cells arrested in the first cell cycle. Cell and nuclear morphology was determined from cells fixed in $70 \%$ ethanol, stained with DAPI, and viewed by fluorescence and light microscopy. Cell viability was determined microscopically from colony formation $24 \mathrm{hr}$ after plating. First cycle arrest was determined by plating cells on solid medium and scoring the percent of cells that arrest in the first cycle fas either large-budded or as two adjacent largebudded cells; see Fig. 1). For each phenotype, at least 100 cells or microcolonies were analyzed.

The fourth criterion is the ability of cells to form colonies when grown at intermediate temperatures (the maximum permissive temperature). This test measures the cumulative effect, over $\sim 20$ cell divisions, of a checkpoint defect in cells limited for a $c d c$ function. The maximum permissive temperature is the temperature $\left(23,25,28,30,32\right.$ or $\left.36^{\circ} \mathrm{C}\right)$ at which cells form macroscopically visible colonies similar to those formed at $23^{\circ} \mathrm{C}$ after $2-4$ days of incubation.

\section{Genetic mapping}

In crosses to generate $c d c 28$ mec1 double mutants we noted their genetic linkage. MEC2 (on CHRXV) and MEC3 (on CHRIV) were each mapped physically by use of DNA fragments from the cloned genes as probes of a Southern transfer of chromosomes separated by pulse-field gel electrophoresis /S. Kim and T. Weinert, unpubl.). We have not yet determined the map position of mec3 on CHRIV; preliminary data indicate that mec3 is not tightly linked to $c d c 2, c d c 13, \operatorname{trp} 1, c d c 34, \operatorname{rad} 9, \operatorname{aro} 8$, or sac2 (T. Weinert et al., unpubl.). Hybridization of a MEC3-containing DNA probe to collections of phage and cosmid recombinant clones, provided by $\mathrm{M}$. Olson, has proven inconclusive thus far in physical mapping ( $T$. Weinert et al., unpubl.).

\section{Acknowledgments}

We thank Theresa Naujack for technical assistance in isolation of mutants. The research was supported by U.S Public Health Service grant GM17709 from the National Institute of General Medical Sciences (L.H.) and GM 45276-01 (T.W.).

The publication costs of this article were defrayed in part by payment of page charges. This article must therefore be hereby marked "advertisement" in accordance with 18 USC section 1734 solely to indicate this fact.

\section{References}

Al-Khodairy F. and A.M. Carr. 1992. DNA repair mutants defining G2 checkpoint pathways in Schizosaccharomyces pombe. EMBO f. 11: 1343-1350.

Amon, A., U. Surana, I. Muroff, and K. Nasmyth. 1992. Regulation of $\mathrm{p} 34^{C D C 28}$ phosphorylation is not required for entry into mitosis in $S$. cerevisiae. Nature 355: 368-371.

Barbet, N.C. and A.M. Carr. 1993. Fission yeast weel protein kinase is not required for DNA damage-dependent mitotic arrest. Nature 364: 824-827.

Boulet, A., M. Simon, G. Faye, G.A. Bauer, and P.M.J. Burgers. 1989. Structure and function of the Saccharomyces cerevisiae $C D C 2$ gene encoding the large subunit of DNA polymerase III. EMBO f. 8: 1849-1855.

Bueno, A. and P. Russell. 1992. Dual functions of CDC6: A yeast protein required for DNA replication also inhibits nuclear division. EMBO I. 11: 2167-2176.

Brinkley, B.R., R.P. Zinkowski, W.L. Mollon, F.M. Davis, M.A. Pisegna, M. Pershouse, and P.N. Rao. 1988. Movement and segregation of kinetochores experimentally detached from mammalian chromosomes. Nature 336: 251-254.

Carson, M.J. 1987. "CDC17, the structural gene for DNA polymerase I of yeast: Mitotic hyperrecombination and effects on telomere metabolism." Ph.D thesis. University of Washington, Seattle.

Dasso, M. 1993. RCCl in the cell cycle: The regulator of chromosome condensation takes on new roles. Trends. Biochem. 18: $96-101$

Dasso, M. and J.W. Newport. 1990. Completion of DNA replication is monitored by a feedback system that controls the initiation of mitosis in vitro: Studies in Xenopus. Cell 61: 811-823. 
Donehower L.A., M. Harvey, B.L. Slagle, M.J. McArthur, C.A. Montgomery, J.S. Butel, and A. Bradley. 1992. Mice deficient for p53 are developmentally normal but susceptible to spontaneous tumours. Nature 356: 215-221.

Eckardt-Schupp, F., W. Siede, and J.C. Game. 1987. The RAD24 $\left(=\mathbf{R}_{1}{ }^{\mathrm{s}}\right)$ gene product of Saccharomyces cerevisiae participate in two different pathways of DNA repair. Genetics 115: 8390.

Enoch, T. and P. Nurse. 1990. Mutation of fission yeast cell cycle control genes abolishes dependence of mitosis on DNA replication. Cell 60: 665-673.

- 1991. Coupling M phase and S phase: Controls maintaining the dependence of mitosis on chromosome replication. Cell 65: 921-923.

Enoch, T. A.M. Carr, and P. Nurse. 1992. Fission yeast genes involved in coupling mitosis to completion of DNA replication. Genes \& Dev. 6: 2035-2046.

Hadwiger J.A., C. Wittenber, M.D. Mendenhall, and S.I. Reed. 1989. The Saccharomyces cerevisiae CKS1 gene, a homolog of the Schizosaccharomyces pombe sucl ${ }^{+}$gene, encodes a subunit of the Cdc28 protein kinase complex. Mol. Cell. Biol. 9: 2034-204l.

Hartwell, L.H. 1976. Sequential function of gene products relative to DNA synthesis in the yeast cell cycle. I. Mol. Biol. 104: 803-817.

- 1992. Defects in a cell cycle checkpoint may be responsible for the genomic instability of cancer cells. Cell 71: 543-546.

Hartwell, L.H. and D. Smith. 1985. Altered fidelity of mitotic chromosome transmission in cell cycle mutants of $S$. cerevisiae. Genetics 110: 381-395.

Hartwell, L.H. and T.A. Weinert. 1989. Checkpoints: Controls that ensure the order of cell cycle events. Science 246: 629634.

Hogan, E. and D. Koshland. 1992. Addition of extra origins of replication to a minichromosome suppresses its mitotic loss in $c d c 6$ and $c d c 14$ mutants of Saccharomyces cerevisiae. Proc. Natl. Acad. Sci. 89: 3098-3102.

Hoyt, M.A., L. Totis, and B.T. Roberts. 1992. S. cerevisiae genes required for cell cycle arrest in response to loss of microtubule function. Cell 66: 507-517.

Jiang, Y., G. Rossi, and S. Ferro-Novick. 1993. Bet2p and Mad2p are components of a prenyltransferase that adds geranylgeranyl onto Yptlp and Sec4p. Nature 366: 84-86.

Jimenez, G., J. Yucel, R. Rowley, and S. Subramani. 1992. The $\mathrm{rad}^{+}$gene of Schizosaccharomyces pombe is involved in multiple checkpoint functions and in DNA repair. Proc. Natl. Acad. Sci. 89: 4952-4956.

Johnston, L.J. and K.A. Nasmyth. 1978. Saccharomyces cerevisiae cell cycle mutant $c d c 9$ is defective in DNA ligase. $\mathrm{Na}$ ture 274: 891-893.

Johnson, L.M., M. Snyder, L.M. Chang, R.W. Davis, and J.L. Campbell. 1985. Isolation of the gene encoding yeast DNA polymerase I. Cell 43: 369-377.

Kastan M.B., O. Onyekwere, D. Sidransky, B. Vogelstein, and R.W. Craig. 1991. Participation of p53 protein in the cellular response to DNA damage. Cancer Res. 51: 6304-6311.

Kelly, T.J., G.S. Martin, S.L. Forsbur, R.J. Stephen, A. Russo, and P. Nurse. 1993. The fission yeast $c d c 18^{+}$gene product couples S phase to start and mitosis. Cell 74: 371-382.

Kuerbitz S.J., B.S. Plunkettt, W.V. Walsh, and M.B. Kastan. 1992. Wild-type p53 is a cell cycle checkpoint determinant following irradiation. Proc. Natl. Acac. Sci. 89: 7491-7495.

Lee, J.M. and A. Bernstein. 1993. p53 mutation increases resistance to ionizing radiation. Proc. Natl. Acad. Sci. 90: 57425746.
Li., J.J. and R.J. Deschaies. 1993. Exercising self-restraint: Discouraging illicit acts of $S$ and $M$ in eukaryotes. Cell 74: 223226.

Li, R. and A.W. Murray. 1991. Feedback control of mitosis in budding yeast. Cell 66: 519-531.

Li, R., C. Havel, J.A. Watson, and A.W. Murray. 1993. The mitotic feedback control gene $M A D 2$ encodes the $\alpha$ subunit of a prenyltransferase. Nature 366: 82-84.

Livingston L.R., A. White, J. Sprouse, E. Livanos, T. Jacks, and T.D. Tisty. 1992. Altered cell cycle arrest and gene amplification potential accompany loss of wild-type p53. Cell 70: 923-935

Matsumoto, T. and D. Beach. 1991. Premature initiation of mitosis in yeast lacking RCC1 or an interacting GTPase. Cell 66: $347-360$.

Murray, A.W. 1993. Creative blocks: Cell-cycle checkpoints and feedback controls. Nature 359: 599-604.

Neff, M. and D.J. Burke. 1992. A delay in the Saccharomyces cerevisiae cell cycle that is induced by a dicentric chromosome and is dependent upon mitotic checkpoints. Mol. Cell. Biol. 12: 3857-3864.

Nishimoto, T., E. Eilen, and C. Basilico. 1978. Premature chromosome condensation in a ts $\mathrm{DNA}^{-}$mutant of BHK cells. Cell 15: 475-483.

Nurse, P. 1990. Universal control mechanism regulating onset of M-phase. Nature 344: 503-508.

Osmani, S.A., D.B. Engle, J.H. Doonan, and N.R. Morris. 1988. Spindle formation and chromatin condensation in cells blocked at interphase by mutation of a negative cell cycle control gene. Cell 52: 241-251.

Osmani, A.H., K. O'Donnell, R.T. Pu, and S.A. Osmani. 1991. Activation of the nimA kinase plays a unique role during mitosis that cannot be bypassed by absence of the bimE checkpoint. EMBO $I$. 10: 2669-2679.

Pringle, P. and L.H. Hartwell. 1981. The Saccharomyces cerevisiae cell cycle. In Molecular biology of the yeast Saccharomyces: Life cycle and inheritance (ed. J.N. Strathern, E.W. Jones, and J.R. Broach), pp. 97-142. Cold Spring Harbor Laboratory, Cold Spring Harbor, New York.

Pringle, J.R., R.A. Preston, A.E.M. Adams, T. Stearns, D.G. Drubin, B.K. Haarer, and E.W. Jones. 1989. Fluorescence microscopy methods for yeast. Methods Cell Biol. 31: 357-432.

Rowley, R., J. Hudson, and P.G. Young. 1992a. The wee1 protein kinase is required for radiation-induced mitotic delay. $\mathrm{Na}$ ture 356: 353-355.

Rowley, R., S. Subramani, and P.G. Young. 1992b. Checkpoint controls in Schizosaccharomyces pombe: rad1. EMBO J. 11: 1335-1342.

Sherman, F., G.R. Fink, and J.B. Hicks. 1986. Methods in yeast genetics. Cold Spring Harbor Laboratory, Cold Spring Harbor, New York.

Sitney, K.C., M.E. Budd, and J.L. Campbell. 1989. DNA polymerase III, a second essential DNA polymerase is encoded by the $S$. cerevisiae CDC2 gene. Cell 56: 599-605.

Slichenmeyer, W.J., W.G. Nelson, R.J. Slebos, and M.B. Kastan. 1993. Loss of p53-associated Gl checkpoint does not decrease cell survival following DNA damage. Cancer Res. 53: $4164-4168$.

Sorger, P. and A.W. Murray. 1992. S-phase feedback control in budding yeast independent of tyrosine phosphorylation of p34 ${ }^{C D C 28}$. Nature 355: 365-368.

Walworth, N., S. Davey, and D. Beach. 1993. Fission yeast chk $1^{+}$portein kinase links the rad checkpoint pathway to cdc2 ${ }^{+}$. Nature 363: 368-371.

Weinert, T.A. and L.H. Hartwell. 1988. The RAD9 gene controls the cell cycle response to DNA damage in Saccharomyces 
cerevisiae. Science 241: 317-322.

1990. Characterization of RAD9 of S. cerevisiae and evidence its function acts posttranslationally in cell cycle arrest after DNA damage. Mol. Cell. Biol. 10: 6554-6564.

1993. Cell cycle arrest of $c d c$ mutants and specificity of the RAD9 checkpoint. Genetics 134: 63-80.

Weinert, T.A. and D. Lydall. 1993. Cell cycle checkpoints, genetic instability and cancer. Sem. Cancer Biol. 4: 129-140.

Yin Y., M.A. Tainsky, F.Z. Bischoff, L.C. Strong, and G.M. Wahl. 1992. Wild-type p53 restores cell cycle control and inhibits gene amplification in cells with mutant p53 alleles. Cell 70: 937-948. 


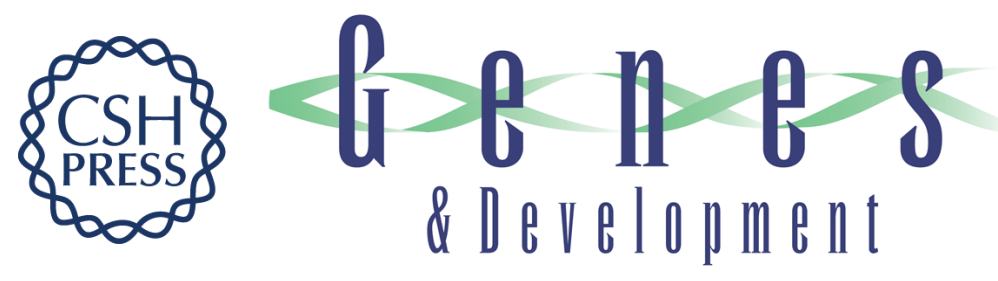

\section{Mitotic checkpoint genes in budding yeast and the dependence of mitosis on DNA replication and repair.}

T A Weinert, G L Kiser and L H Hartwell

Genes Dev. 1994, 8:

Access the most recent version at doi:10.1101/gad.8.6.652

References This article cites 51 articles, 14 of which can be accessed free at:

http://genesdev.cshlp.org/content/8/6/652.full.html\#ref-list-1

License

Email Alerting

Service

Receive free email alerts when new articles cite this article - sign up in the box at the top right corner of the article or click here.

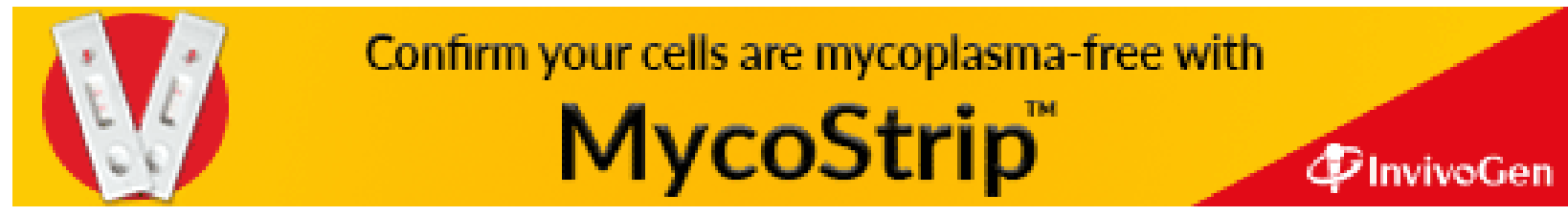

